\title{
Increased Adrenal Secretion of Norepinephrine and Epinephrine after Endotoxin and Its Reversal with Corticosteroids
}

\author{
RICHARD L. PRAGER, M.D., ERNEST L. DUNN, M.D., AND JOHN F. \\ SEATON, B.SC. \\ Department of Surgery, The University of Michigan Medical Center, \\ Ann Arbor, Michigan 48104
}

Submitted for publication December 11, 1974

There are many articles in the medical and surgical literature investigating the diagnosis, pathophysiology, and treatment of endotoxin shock. However, the information concerning catecholamine release after endotoxin is not well clarified. The present study was undertaken to describe precisely the dynamics of catecholamine release after endotoxin and, in addition, to ascertain the effect of pharmacologic doses of synthetic corticosteroids on the catecholamine response to endotoxin.

\section{MATERIALS AND METHODS}

Ten adult mongrel dogs, weighing between 15 and $25 \mathrm{~kg}$, were studied under intravenous pentobarbital anesthesia, $30 \mathrm{mg} / \mathrm{kg}$. A cuffed endotrachael tube was inserted and ventilation accomplished with a Harvard volume respirator using $98 \%$ oxygen and $2 \%$ $\mathrm{CO}_{2}$ at a tidal volume of $20 \mathrm{cc} / \mathrm{kg}$. Intravenous Ringer's lactate was administered at $100 \mathrm{cc} / \mathrm{hr}$ to all animals and the arterial pH was maintained in a physiologic range with intravenous sodium bicarbonate. Heparin was administered intravenously, $1 \mathrm{mg} / \mathrm{kg}$, prior to cannulations and the same dose repeated hourly. Left adrenal vein to left femoral vein shunts were placed. A polyethylene catheter with a thermal dilution thermister attached was placed in the aortic arch via the carotid

This investigation was supported by NIH Grant HL I4053 and the Upjohn Pharmaceutical Company.

We gratefully acknowledge the interest and support of Drs. Marvin M. Kirsh and Timothy S. Harrison. artery and a central venous catheter was inserted into the right atrium via the right external jugular vein. Cardiac output was determined by the thermal dilution technique. Mean arterial pressure and central venous pressure were recorded by means of Statham transducers and the Electronics for Medicine recorder. Continuous lead II EKG's were visualized. Baseline adrenal venous flow in $\mathrm{cc} / \mathrm{min}$ and arterial and adrenal venous catecholamines (trihydroxyindole technique) [1] were determined. Ten cubic centimeters of adrenal venous effluent were withdrawn at each sampling and adrenal catecholamine secretion rates calculated as a function of adrenal venousarterial catecholamine differences related to adrenal flow rate. After these baseline determinations, animals were divided into two groups of five dogs each. Group I animals received $0.5 \mathrm{mg} / \mathrm{kg}$ of $E$. coli endotoxin $\left(\mathrm{LD}_{60}\right)^{1}$ injected intravenously in $10 \mathrm{cc}$ normal saline over $5 \mathrm{~min}$. All studies were repeated at $15,30,60,120$, and $180 \mathrm{~min}$ after endotoxin. After the 180-min observations, the animals were bled to a mean blood pressure of 50 , stabilized for $10 \mathrm{~min}$, and all studies repeated.

After initial baseline studies, Group II animals, received intravenous methyl prednisolone sodium succinate $(30 \mathrm{mg} / \mathrm{kg})$ over 5 min. They were observed for $30 \mathrm{~min}$ and a second set of baseline determinations obtained. At this point, as in the Group I ani-

${ }^{1}$ Difco Laboratories, Detroit, MI. 
TABLE 1

Group I Response to Endotoxin

\begin{tabular}{|c|c|c|c|c|c|c|}
\hline & \multicolumn{2}{|c|}{$\begin{array}{c}\text { Plasma catecholamines } \\
(\mu \mathrm{g} / \text { liter })\end{array}$} & \multicolumn{2}{|c|}{$\begin{array}{c}\text { Adrenal secretion } \\
\text { of catecholamines } \\
(\mu \mathrm{g} / \mathrm{min})\end{array}$} & \multirow{2}{*}{$\begin{array}{l}\text { Mean arterial } \\
\text { pressure } \\
\text { (mmHg) }\end{array}$} & \multirow{2}{*}{$\begin{array}{r}\text { Cardiac index } \\
\left(\text { liters } / \mathrm{min} / \mathrm{m}^{2} \text { ) }\right.\end{array}$} \\
\hline & Epi. & $\mathrm{NE}$ & Epi. & $\mathrm{NE}$ & & \\
\hline Baseline & 1.675 & 0.051 & 0.157 & 0.058 & 129 & 1.97 \\
\hline $15 \mathrm{Min}$ & 2.339 & 0.080 & $0.493 P<0.05$ & $0.20 \quad P<0.05$ & 85 & 1.13 \\
\hline $30 \mathrm{Min}$ & 2.92 & 0.434 & 0.332 & 0.123 & 111 & 1.67 \\
\hline $60 \mathrm{Min}$ & $5.99 P<0.01$ & 1.07 & $0.822 P<0.05$ & $0.305 P<0.05$ & $92 P<0.05$ & 1.39 \\
\hline $120 \mathrm{Min}$ & 4.66 & 0.540 & 0.563 & $0.319 P<0.02$ & $62 P<0.001$ & $1.00 P<0.05$ \\
\hline $180 \mathrm{Min}$ & 4.19 & 0.809 & 0.366 & $0.326 P<0.01$ & $83 P<0.01$ & $1.10 P<0.05$ \\
\hline Hemorrhage & 10.43 & 1.51 & $0.679 P<0.02$ & $0.555 P<0.01$ & $34 P<0.001$ & $.44 P<0.01$ \\
\hline
\end{tabular}

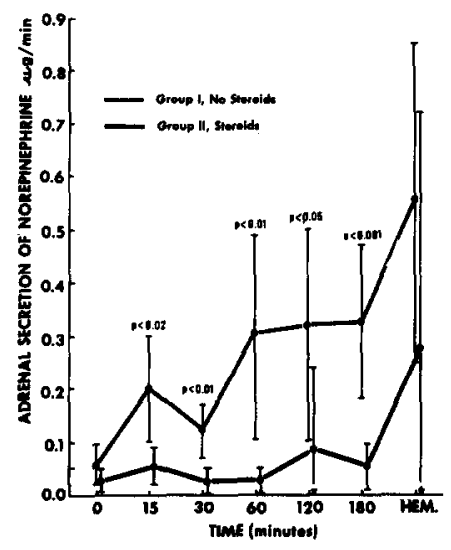

FIG. 1. Mean adrenal sccretion of norepinephrine \pm $1 \mathrm{SD}$ is shown in the non-steroid- and steroid-treated animals after endotoxin.

mals, $E$. coli endotoxin $0.5 \mathrm{mg} / \mathrm{kg}\left(\mathrm{LD}_{60}\right)$ was injected over $5 \mathrm{~min}$ intravenously. All studies were then repeated exactly as in Group I. Animals in both groups were sacrificed at the conclusion of the experimental period.

\section{EXPERIMENTAL RESULTS}

The Group I animals demonstrated increased adrenal secretion of norepinephrine at $15 \mathrm{~min}(P<0.05),{ }^{2} 60 \mathrm{~min}(P<0.05)$, $120 \min (P<0.02), 180 \mathrm{~min}(P<0.01)$, and after hemorrhage $(P<0.01)$ when compared to their baseline. These animals also showed increased adrenal secretion of epinephrine at $15 \mathrm{~min}(P<0.05), 60 \mathrm{~min}$ $(P<0.05)$, and after hemorrhage $(P<$ 0.02). Furthermore, animals in this group

${ }^{2}$ All results were analyzed using Student's $t$ test. experienced hypotension beginning at $60 \mathrm{~min}$ $(P<0.05)$ and this continued for the remainder of the experiment. Cardiac index fell to approximately $50 \%$ of baseline at $\mathbf{1 2 0}$ $\min (P<0.05)$ and continued decreasing for the remainder of the experiment (Table 1).

The Group II, steroid-pretreated dogs, demonstrated lower adrenal secretion of norepinephrine at all samplings, $15 \mathrm{~min}$ through $180 \mathrm{~min}(P<0.02-P<0.001)$ (Fig. $1)$, and epinephrine $(P<0.05)$ at 30 and 60 min when compared to Group I animals (Fig. 2). In addition, the arterial plasma epinephrine levels were lower in the Group II animals at $60 \mathrm{~min}(P<0.01)$ (Fig. 3). There was no difference in arterial plasma norepinephrine between the two groups (Fig. 4). There was no difference with reference to

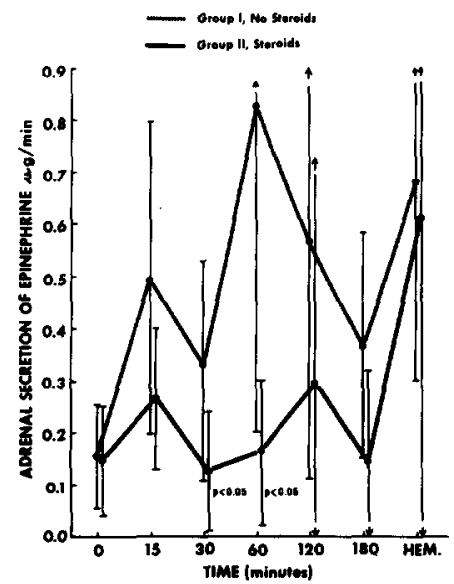

FIG. 2. Mean adrenal secretion of epinephrine \pm 1 SD is shown in the non-steroid- and steroid-treated animals after endotoxin. 


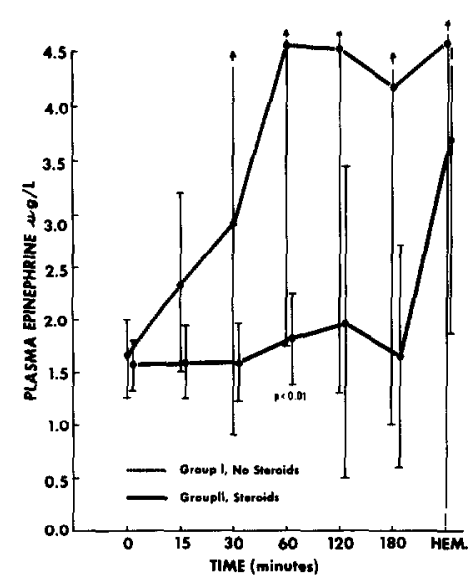

FIG. 3. Mean arterial plasma epinephrine \pm 1 SD is shown in the non-steroid- and steroid-treated animals after endotoxin.

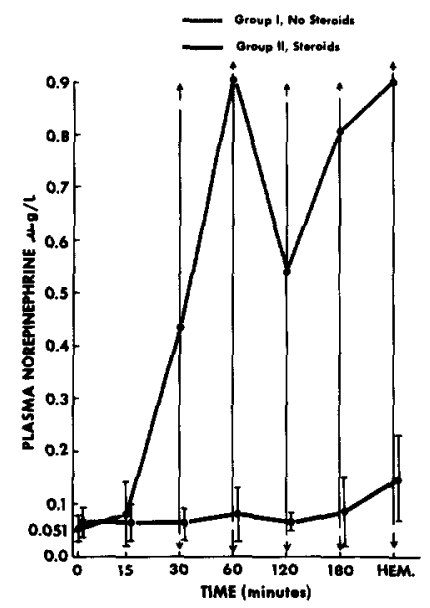

FIG. 4. Mean arterial plasma norepinephrine \pm 1 SD is shown in the non-steroid- and steroid-treated animals after endotoxin. cardiac index, mean blood pressure, and peripheral vascular resistance between the two groups (Table 2).

\section{DISCUSSION}

The response of the adrenergic nervous system after endotoxin has not been entirely clarified. Furthermore, the effects of steroids in various forms of shock has often been contradictory. This paper has attempted to combine these two facets of research in defining the effects of corticosteroids on the sympathoadrenal system in endotoxin shock.

In 1959 Egdahl [3] studied adrenal venous catecholamines in dogs after an intravenous endotoxin injection. He demonstrated that the response of the adrenal medulla to endotoxin was dependent upon the dose of endotoxin and, furthermore, that intact neuronal pathways were necessary for the adrenal medulla to respond to endotoxin. In his study entitled "The participation of the adrenal gland in endotoxin shock," Hökfelt [5] reported that, although adrenal flow dropped after endotoxin administration to cats, the minute output of catecholamines increased. Norepinephrine was the catecholamine initially elevated and epinephrine was increased toward the end of the observation period. In addition, Hökfelt confirmed the finding of Egdahl that adrenal response after endotoxin involved a neurogenic mechanism and that the adrenal response was maximal in the terminal stages of endotoxin shock. Heiffer [4], on the other

TABLE 2

Comparison of Peripheral Vascular Resistance, Blood Pressure, and Cardiac Index Between Groups I and II

\begin{tabular}{|c|c|c|c|c|c|c|c|c|c|}
\hline & \multicolumn{3}{|c|}{$\begin{array}{l}\text { Total peripheral resistance } \\
(\mathrm{mmHg} / \mathrm{ml} / \mathrm{sec})\end{array}$} & \multicolumn{3}{|c|}{$\begin{array}{c}\text { Mean blood pressure } \\
(\mathrm{mmHg})\end{array}$} & \multicolumn{3}{|c|}{$\begin{array}{l}\text { Cardiac index } \\
\text { (liters } / \mathrm{min} / \mathrm{m}^{2} \text { ) }\end{array}$} \\
\hline & Group I & & Group II & Group I & & Group II & Group I & & Group II \\
\hline Baseline & 5.86 & $P<0.6$ & 6.42 & 129 & $P<0.9$ & 130 & 1.97 & $P<0.4$ & 1.59 \\
\hline $15 \mathrm{Min}$ & 6.47 & $P<0.3$ & 5.42 & 85 & $P<0.7$ & 76 & 1.13 & $P<0.8$ & 1.07 \\
\hline $30 \mathrm{Min}$ & 5.42 & $P<0.3$ & 4.30 & 111 & $P<0.2$ & 88 & 1.67 & $P<0.4$ & 1.51 \\
\hline $60 \mathrm{Min}$ & 5.84 & $P<0.3$ & 4.80 & 92 & $P<0.8$ & 90 & 1.39 & $P<0.8$ & 1.47 \\
\hline $120 \mathrm{Min}$ & 5.22 & $P<0.5$ & 4.68 & 62 & $P<0.1$ & 81 & 1.00 & $P<0.3$ & 1.32 \\
\hline $180 \mathrm{Min}$ & 6.50 & $P<0.6$ & 5.86 & 83 & $P<0.8$ & 80 & 1.10 & $P<0.9$ & 1.07 \\
\hline Hemorrhage & 7.30 & $P<0.7$ & 6.69 & 34 & $P<0.2$ & 44 & .44 & $P<0.5$ & .53 \\
\hline
\end{tabular}


hand, demonstrated in rabbits that after endotoxin there was no immediate increase in circulating norepinephrine or epinephrine suggesting that the sympathetic nervous system was in some fashion depressed by the endotoxin. Our results support the observations of Hökfelt, since we were able to demonstrate increased adrenal secretion of both epinephrine and norepinephrine in the nonsteriod Group I animals at $15 \mathrm{~min}$ and 60 $\min$ and in addition, after endotoxin, norepinephrine secretion remained elevated during the remainder of the experiment. Plasma elevations of catecholamines were not significant except for $P<0.01$ at $1 \mathrm{hr}$ for epinephrine; therefore, ruling out the peripheral adrenergic nervous system as a source for the elevations found in adrenal venous effluent. Futhermore, our data do not corroborate those of Rosenberg and Lillehei [7] who speculated that endotoxin may have the ability to "temporarily deplete" peripheral stores of norepinephrine in animals subjected to endotoxin shock. The nonsteroid-treated animals (Group I) were able to raise their plasma catecholamines in a nearly stepwise fashion over the 3-hr observation period and responded with generous outpourings, albeit not significant, of epinephrine and norepinephrine in response to hemorrhage.

After the pharmacologic dose of steroid plus endotoxin, the adrenal gland reacted by lowering its secretion of both norepinephrine and epinephrine. Adrenal secretion of norepinephrine in response to endotoxin appeared affected to a greater degree by steroids since its adrenal secretion was lower during the entire 3-hr observation period. Adrenal epinephrine release was also diminished. The peripheral adrenergic nervous system may be less affected by the corticosteroids since the plasma norepinephrine was no different between the two groups of dogs although epinephrine showed a trend to lower output. It is noteworthy that the adrenal gland and the peripheral adrenergic nervous system were able to react to hemorrhage in a similar fashion in both groups, indicating that the medulla and sympathetic nervous system were not totally blocked by the massive steroid administration.

A great deal has been written about the use of corticosteriods in endotoxin shock and their myriad salutatory effects ranging from an inotropic effect on the heart, to stabilizing cellular membranes and acting as vasodilators [6]. This is, however, very little direct evidence of steroid effect(s) on the adrenergic nervous system. Sambhi and Weil [8], in analyzing the pharmacodynamic effects of glucocorticoids, showed that large doses of glucocorticoids produced a decrease in total peripheral resistance in normal patients and patients in shock. Although catecholamines were not measured in their study, they felt that this action of glucocorticoids could be a direct effect on peripheral vessels or a primary myocardial effect with secondary peripheral effects of vasodilatation. Dietzman, in an experimental and clinical report on the treatment of low cardiac output syndrome [2] showed a decrease in total peripheral resistance in dogs after $30 \mathrm{mg} / \mathrm{kg}$ of methyl prednisolone along with elevated plasma catecholamines which apparently remained unaffected by the pharmacological dose of steroids. The present study demonstrated no significant change in total peripheral resistance or cardiac index between the steroid and nonsteroid shock dogs while demonstrating as did Dietzman, elevated peripheral plasma catecholamines in shock.

In this study large doses of synthetic glucocorticoid actually blunted adrenal catecholamine output in shock when increased catecholamine secretion was expected. Indeed, the unanswered question remains why catecholamine secretion is diminished by pharmacologic doses of synthetic corticosteroids. Coupland [9] in 1953 was the first to allude to an effect of the adrenal cortex's glucocorticoids on the adrenal medulla. In 1966 Wurtman and Axelrod [10] defined this effect of glucocorticoids on phenylethanolamine $N$-methyl transferase, the enzyme that methylates norepinephrine; in the presence of glucocorticoids, epinephrine is synthesized in the chromaffin cell (Fig 5). 

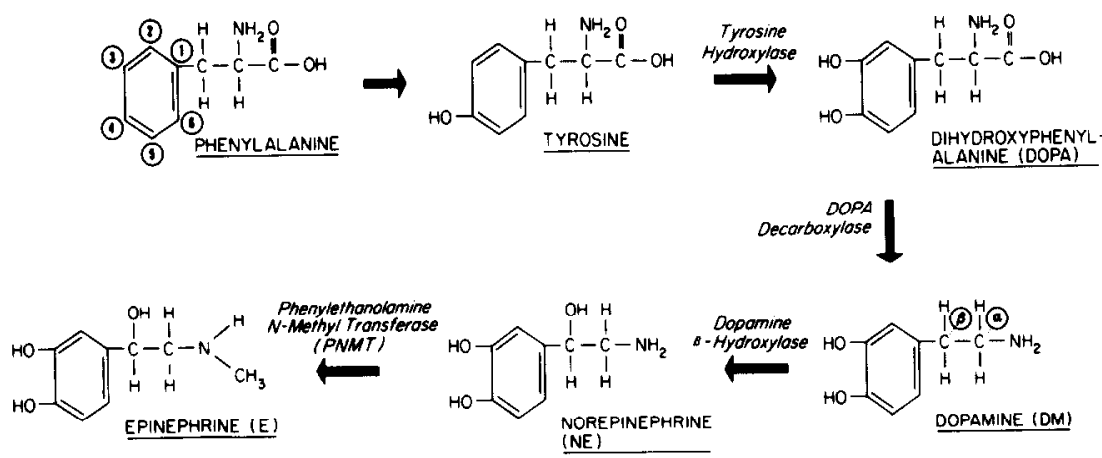

FIG. 5. Biosynthesis of catecholamines.

Furthermore, although others have demonstrated decreased peripheral resistance after massive steroids even with high levells of circulating catecholamines, we showed decreased adrenal catecholamines and yet were unable to demonstrate a lowered peripheral resistance. Had we done so, we might have been able to account for the purported vasodilatory effect of steroids. Nevertheless, pretreatment with pharmacologic doses of synthetic corticosteriods exerts a specific effect on the adrenal medulla in endotoxin shock that profoundly limits adrenal catecholamine release.

\section{SUMMARY}

Two groups of dogs were subjected to an $\mathrm{LD}_{60}$ of $E$. coli endotoxin. Group II animals were pretreated with $30 \mathrm{mg} / \mathrm{kg}$ of methyl prednisolone sodium succinate before the intravenous endotoxin. All animals had hypotension and diminished cardiac index after endotoxin administration.

The nonsteroid dogs, Group I, demonstrated increased adrenal secretion of norepinephrine and epinephrine. Arterial plasma catecholamines were comparable. Group II steroid-treated animals demonstrated lower adrenal secretion of norepinephrine and epinephrine when compared to Group I, nonsteroid animals. These results demonstrate that pretreatment with pharmacologic doses of synthetic corticosteroids exerts a specific effect on the adrenal medulla in endotoxin shock that profoundly limits adrenal catecholamine release.

\section{REFERENCES}

1. Cruut, J. R. Calecholamines, Standard Methods of the American Association of Clinical Chemistry, Vol. 3, pp. 62-79. Academic Press, New York, 1962.

2. Dietzman, R., Castaneda, A. R., Lillehei, C. W., Ersek, R. A., Motsay, G. J., and Lillehei, R. C. Corticosteroids as effective vasodilators in the treatment of low output syndrome. Chest 57:440, 1970.

3. Egdahl, R. H. The differential response of the adrenal cortex and medulla to bacterial endotoxin. J. Clin. Invest. 38:1120, 1959.

4. Heiffer, M. H., Mundy, R. L., and Mehlman, B. Effect of lethal doses of bacterial endotoxin ( $E$. coli) on sympathetic neurohormones in the rabbit. $\mathrm{Am}$. J. Physiol. 198:1307, 1960.

5. Hökfelt, B., Bygdeman, S., and Sekkenes, J. The participation of the adrenal glands in endotoxin shock. In K. D. Bock (Ed.), Shock-Pathogenesis and Therapy, pp. 151-161. Springer-Verlag, Berlin, 1962.

6. Motsay, G., Dietzman, R. H., Ersek, R. A., and Lillehei, R. C. Hemodynamic alterations and results of treatment in patients with gram-negative septic shock. Surgery 67:577, 1970.

7. Rosenberg, J. C., Lillehei, R. C., Longerbeam, J., and Zimmermann, B. Studies on hemorrhagic and endotoxic shock in relation to vasomotor changes and endogenous circulating epinephrine, norepinephrine and serotonin. Ann. Surg. 154:611, 1961.

8. Sambhi, M., Weil, M. H., and Udhoji, V. N. Acute pharmacodynamic effects of glucocorticoids. Circulation $31: 523,1965$.

9. Wurtman, R. Catecholamines. Pp. 10-11, Little Brown, Boston, 1966.

10. Wurtman, R. J., and Axelrod, J. Control of enzymatic synthesis of adrenaline in the adrenal medulla by adrenal cortical steroids. J. Biol. Chem. 241 :2301, 1966. 